\title{
INFORMATION
}

\section{MODELS OF MENTORING IN LANGUAGE TEACHER EDUCATION}

\author{
Nguyen Thi Mai Hoa
}

\section{New York: Springer, 2017}

\author{
Do Thi Xuan Hoa*
}

Faculty of English Language Teacher Education, VNU University of Languages and International Studies, Pham Van Dong, Cau Giay, Hanoi, Vietnam

\begin{abstract}
Mentoring in foreign language teacher education, be it official and organized programs or informal sharing and discussion with colleagues, has been widely recognized as a powerful means to assist pre-service and novice teachers in improving their teaching practice. Much as each teacher's personal and anecdotal appreciation of this activity's effectiveness, little

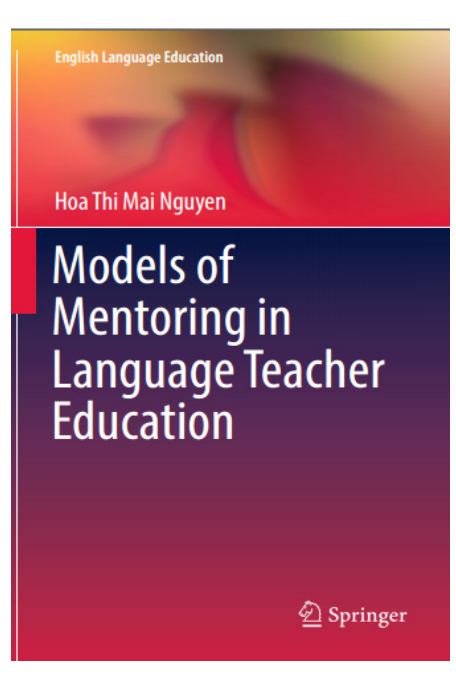
about mentoring has been empirically researched and comprehensively presented. In fact, mentoring for foreign language teacher students and early-career teachers is still underexplored. Among available references, Models of Mentoring in Language Teacher Education (Nguyen, 2017) is the latest and most informative book that gives teacher educators, mentors and policy makers comprehensive literature about mentoring and research-based recommendations and guidelines to successful implementation of mentoring and peer mentoring within the Asian teaching context.

\footnotetext{
* Tel.: 84-964863288

Email: xuanhoa.do@gmail.com
}

With ten chapters in total, the book appears as a complete work in the field of mentoring for EFL teachers in one Asian context. Chapters 1 and 2 discuss the overall situation of English language teacher training in Vietnam and theoretical background that underpins the use of mentoring in English language teacher training and retraining. A substantial part of chapter two is devoted to discussing theoretical frameworks for mentoring and peer mentoring with a clear focus on two major functions of a peer-based professional relationship including career-related functions (information sharing, career strategizing and job related feedback) and psychosocial functions (confirmation, emotional support, personal feedback and friendship). Highlights of these two chapters are the arguments that mentoring-related issues in both pre-service teacher education and in-service teacher professional development found in Vietnam are similar to other settings in Asia, suggesting that the book will be relevant to teachers and educators in Asia in general besides its stated target readers. 
Chapters from 3 to 9 comprise the bulk of the book with insightful discussions on pre-service teachers' perception of mentoring activities during their practicum, qualities expected of mentors for effective mentorship, group mentoring as an activity to develop pre-service teachers' reflection and peer mentoring as a means to professionally and emotionally assist pre-service and beginning teachers. The main part of these chapters are the author's succintly reported research projects on mentoring activities with different groups of participants in Vietnam over a number of years. These studies are presented and discussed in light of relevant body of literature in the field.

The qualitative study in chapter 3 reveals the pre-service teacher participants' expectations of a successful practicum and their awareness of both positive support and problems they experienced during their practicum. Some participants appreciated their mentors being caring and supportive of their creativity while many others expressed disappointment with their mentors' inadequate feedback on their lessons, unreasonable expectations and requirements and their lack of professionalism. Findings from this chapter are not surprising to those who have been involved in school-based practicum; however, the author did provide a number of practical implications for more effective school-based teaching placement. Teacher educators can benefit from the suggestions that teacher students should take a proactive role in their own learning rather than depending on their mentors and that school mentors need to be rigorously selected and equipped with mentoring skills.

Chapter 4 draws on chapters 3 and 5 to give an overview of a formal mentoring program which stresses a mentor's expected personal traits, mentor-mentee matching and mentor training. These themes are discussed again in chapter 9, which is about problems pertaining to implementing peer mentoring. Readers interested in learning more about conducting successful mentoring programs for beginning EFL teachers are likely to find chapters 4 and 9 highly relatable. Important themes such as mentors' expected personal qualities, mentor-mentee matching and peer mentoring training are repeated in these two chapters, implying that these are factors that should be carefully considered and planned. Though the list of mentors' expected personal qualities is relatively predictable, and not particularly useful, the section on grouping colleague mentors and mentees based on their similarities in characteristics, career goals, experiences, work ethics and the like and the one on equipping both mentors and mentees with mentoring skills provide thoughtprovoking ideas to implement effective peer mentoring programs.

Chapter 5 further discusses group peer mentoring, a model that boosts pre-service teachers' reflective practice during their teaching placement. Major findings from this qualitative case study include a fairly high level of reflection among the participants with comparative reflection being the most common form of reflection followed closely by descriptive reflection and critical reflection. Observation, post-observation discussion, time and a supportive environment are reported to be the factors that foster reflection among the participants. Finishing chapter 5, readers can recognize a clear link between this chapter and the previous ones. With chapter 3 emphasizing the important role of teacher students' dependence and responsibilities as adult learners, chapter 5 highlights teacher students' reflection induced by group peer mentoring. The author purposely built one chapter upon another to gradually argue for group mentoring and peer 
mentoring as a valuable opportunity for preservice teachers to learn from one another to become independent learners and reflective practitioners, rather than taking in knowledge and mimicking lessons from an experienced teacher like in conventional mentoring. This line of argument seems smart and truly persuasive. Wallace (1994) once proposed a framework for foreign language teacher education and development including three models: the applied science model, the craft or mentoring model and the reflective teaching model. It is clear that the author's studies in chapter 3 and 5 lend themselves closely to Wallace (1994)'s framework and provide strong evidence and arguments for fostering foreign language teachers' habit of reflecting on their own classroom practices and their effects and what constraints there are. Murray and Christison (2011) view it the same way when categorizing peer coaching as a reflective approach to sustainable development for foreign language teachers. They believe that peer coaching puts together teachers who are committed to improving "their craft" (p. 203) and delivering more effective lessons and who are willing to give descriptive, specific and change-oriented feedback to their own and their colleagues' classroom activities.

Chapter 6 and 7 report a quasiexperimental pre- and post-test design study which confirms the significant influence of formal peer mentoring on pre-service teachers' professional practice. Comparing two groups of participants' performance and surveying their feedback, the author found that by participating in formal peer coaching, preservice teacher participants in the treatment group made more impressive progress in their lesson planning and preparation, classroom management, giving instructions and professional responsibilities than the control group. The author devoted the whole chapter 7 to discussing the kinds of support the student teachers received. The findings and discussion sections in this chapter are very much similar to the contents of chapter 2, which is also about psychological support and career-related support that pre-service teachers draw from their mentors.

Chapter 8 is a discussion of a peer mentoring program conducted for beginning teachers. A number of themes such as self-reflection (chapter 5) and psychological support (chapters 2 and 7) are discussed again in this chapter. The repetition, however, does not become tedious, but provides surprising insights into the actual effectiveness of peer mentoring for beginning teachers. While the teacher mentees in the study appreciated their colleague mentor's feedback on their lesson, they did not have enough time to explain their practice and did not feel frank enough to comment on their mentor's lessons. What can be learnt from this is that a more appropriate amount of time should be allocated for post-observation feedback and that mentors should be trained prior to engaging in mentoring activities. Another useful contribution to the current literature about a mentor-mentee relationship is that peer mentoring among novice teachers could turn a hierarchical relationship into an equal and friendly companionship in which teachers support each other in both professional and personal life. In this chapter, readers can also recognize that the theme of self-reflection is discussed again. It seems very clear that the author is a strong advocate of developing EFL teachers' reflective practice in different professional development activities.

Chapter 10 closes the book with a number of final remarks that stress the pivotal role of mentoring in teachers' professional development and the conditions for effective mentorship. In short, the volume is not only a comprehensive body of literature on 
mentoring for foreign language teachers but also a collection and presentation of the author's studies on mentoring, which provides updated and valid findings and implications for teacher trainers and other concerned readers.

The discussion on mentoring in this volume is concise and reader-friendly, without over-simplifying the complex theoretical rationales for mentoring including social constructivism, collaborative reflection, teacher learning, and the foundational theories for group and peer mentoring, which reflects the author's extensive expertise in the field. Each and every issue related to mentoring is explained in detail and supported by ample relevant literature and research evidence. This volume can, therefore, be used a reliable and rich source of references for EFL teacher readers and emerging researchers interested in mentoring activities. Similarly, the whole volume, particularly sections reporting the author's research project in each chapter, is a standard sample of a strong and succinct academic research writing style. As a researcher writer, the author neatly reports a good range of methodologies and designs of the studies she conducted. Emerging researchers can definitely extract certain paragraphs and arguments for the choice of different research designs, data collection and analysis instruments for their own reference. In his review of Nguyen (2017), Stewart (2017) refers to the author's research in this volume as "assiduous" as a way to acknowledge her well designed and pithily expressed studies.

Readers who have been involved in mentoring activities would not find it hard to notice that the majorities of studies on different aspects of mentoring reported in this book were mostly done with pre-service teachers in Vietnam during their practicum (Chapters $3,4,5,6,7$, and 9). While all the studies were thoroughly designed and conducted and their implications are of great help to teacher educators particularly, it cannot be denied that mentoring itself is a long-term professional development activity that is more applicable to in-service teachers than pre-service teachers who are only engaged in mentoring for 4 to 6 weeks of their practicum. This means that the book would provide more relevant findings and practical implications if more novice teachers were included as participants. Having said that, it has to be pointed out that in Vietnam and other Asian contexts, the practice of classroom observation and reflection among in-service teachers is not yet widely conducted (Pham, 2001), whereas for teacher students, practicum is a required component of their program, meaning that in terms of availability and practicality, teacher students would conveniently make up the main group of the participants in the reported studies.

Regarding training mentors, the author introduces three training models and emphasizes cherry-picking strategies from each model rather than adopting one. She also reports a qualitative study examining the mentors' evaluation of four 60-minute mentor orientation sessions they attended (Chapter 9). Despite a brief description of the mentoring training activities, the frequency of the four 60 -minute mentor training sessions was not reported. The participants' comments on the speed and effectiveness of the sessions should, therefore, be discussed with caution. What feels unsatisfactory in the study is the absence of the participants' evaluation of the mentoring training after they worked as mentors, which could reflect their awareness and acknowledgement of the benefits of what they had referred to as "theoretical" or "formal" right after the training sessions. Interested readers would also expect more 
specific and practical guidelines on preparing inexperienced mentors for their tasks. An appendix that describes in full detail highly effective mentoring training activities would be much appreciated.

In conclusion, the author made an impressive effort in writing up this comprehensive volume which concisely summarizes literature on mentoring, clearly presents different viable mentoring models and strongly advocates the model of formal peer mentoring as a professional development activity for teacher students and beginning teachers. Teacher students, teachers, teacher educators and policy makers benefit from the soundness of studies conducted and reported in the volumes and the practicality of suggestions for conducting mentoring activities that fit differing contexts.

\section{References}

Murray, D. E. \& Christison, M. (2011). What English language teachers need to know (I): Understanding learning. London: Routledge.

Pham, H. H. (2001). Teacher development: A real need for English departments in Vietnam. English Teaching Forum, 39(4). Retrieved from http:// exchanges.state.gov/englishteaching/forum/ archives/2001/01-39-4.html

Stewart, T. (2017). Models of Mentoring in Language Teacher Education/Reviews. Retrieved from https://www.springer.com/gp/ book/9783319441498\#reviews

Wallace, M. (1994). Training foreign language teachers: $A$ reflective approach. Cambridge: Cambridge University Press. 